\title{
LOS ANUARIOS DE FOTOGRAFÍA EN ESPAÑA DE 1946 Y 1948 EDITADOS POR LA REVISTA SOMBRAS
}

\author{
Juan Miguel Sánchez Vigil y María Olivera Zaldua \\ UNIVERSIDAD COMPLUTENSE DE MADRID
}

Si la fotografía no es un arte clásico, es, por lo menos, el medio de expresión de muchos artistas.

Eduardo Susanna

Anuario Sombras, 1946

El primer anuario sobre fotografía española se publicó antes de la guerra civil, en 1924, y hasta casi un cuarto de siglo después, en 1946, no salió el segundo, editado por la revista Sombras, órgano de difusión de la Real Sociedad Fotográfica de Madrid. El objetivo fue mostrar la fotografía del momento, presentando las creaciones y las novedades técnicas. Con el mismo propósito, esa institución editó un segundo anuario en 1948, con estructura y contenidos similares. Ambas publicaciones contienen documentación fundamental para el estudio de los autores y sus obras, el desarrollo profesional y amateur, las sociedades y agrupaciones fotográficas, así como de la evolución técnica. Se realiza en este artículo un análisis de ambos anuarios con el objetivo de aportar nuevos datos a la historia de la fotografía española desde los aspectos artístico, informativo y documental.

Palabras clave: Anuario fotográfico; Arte fotográfico; Fotografía; Historia de la fotografía española; revista Sombras.

\section{SPAIN'S PHOTOGRAPHY YEARBOOKS OF 1946 AND 1948, PUBLISHED BY SOMBRAS MAGAZINE}

The first yearbook of Spanish artistic photography was published before the Civil War in 1924, but it was not until twenty-five years later that the second one was printed by Sombras magazine, of the Real Sociedad Fotográfica de Madrid. It was intended to reflect the situation of photography at the time by presenting the latest creations and technical innovations. With this same goal in mind, that society published a second yearbook in 1948, with similar structure and contents. Both publications contain basic documentation for the study of the photographers and their works, professional and amateur development, photographic associations and groups, as well as technical evolution. Both yearbooks are analyzed in this article in order to provide new information on the history of Spanish photography from the artistic, informative and documentary points of view.

Key words: Photographic yearbook; Photographic Art; Photography; History of Spanish Photography; Sombras magazine. 


\section{Introducción}

La historia de la fotografía tienes muchas lecturas, y fundamentalmente tres relacionadas con la autoría, la ubicación temporal y espacial, y los contenidos. Anne McCuley ha considerado que "El concepto de historia única y lineal de la fotografía también fracasa a la hora de abordar los problemáticos límites de lo fotográfico"1. Por lo que respecta al estudio histórico se han aplicado diversas metodologías, desde la cronológica hasta la obra de autor, si bien todos los planteamientos están sometidos a debate por los investigadores ${ }^{2}$. Una de las fuentes fundamentales en la investigación sobre la materia son los anuarios, cuyo valor en un espacio y tiempo concretos es de gran importancia ya que son un referente de la creación y las tendencias, si bien absolutamente

\section{ANNU AIRE}

\section{PHOTOGRAPHIQUE}

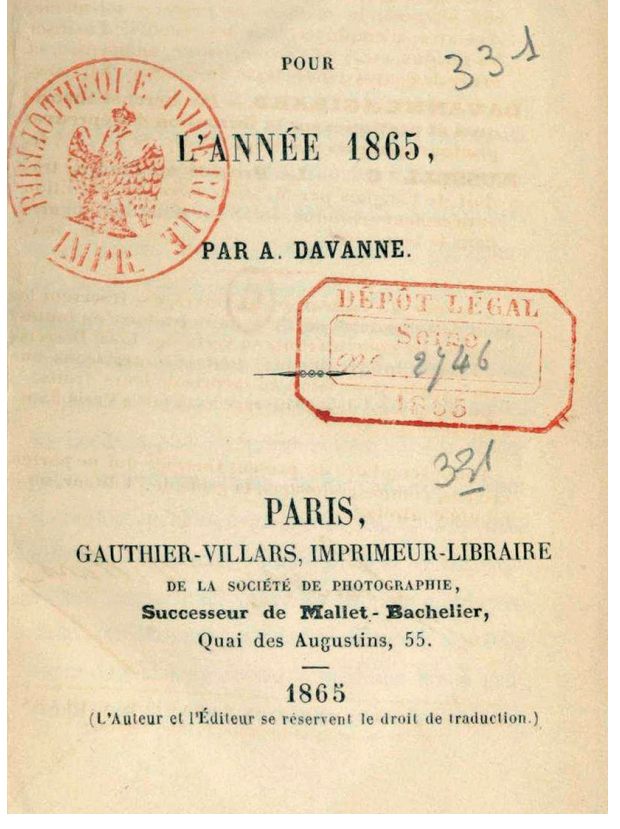

Fig. 1. Annuaire Photographique. París, 1865. subjetivo cuando se trata de selecciones con criterios particulares como en el caso que nos ocupa. Aún así, al tratarse de obras de referencia son claves en toda investigación, como se indica en la definición del Diccionario Enciclopédico de las Ciencias de la Documentación: "Documento que recoge los últimos acontecimientos producidos a lo largo de un año sobre diferentes materias y contenidos" ${ }^{3}$. Por consiguiente los matices serán diversos en función de la entidad que los publica, los objetivos y el tipo de información recopilada.

El primer anuario de fotografía fue editado en Francia por Alphonse Davanne en 1865, apenas un cuarto de siglo después de que Daguerre presentara su invento en París. Se tituló Annuarie photographique (fig.1) y su contenido fue sobre procedimientos e innovaciones. Treinta años después, en 1895, Francis James Mortimer comenzó a editar en Londres el anuario Photograms of the year, dando ya tanto valor a los autores y a sus obras como a la técnica.

En España, el primer anuario salió en 1924 y hasta 1946 no se publicaría el segundo, evidenciando un claro distanciamiento con Europa. Algunos historiadores han considerado como primer anuario de la fotografía española el editado por la Agrupación Fotográfica Almeriense (Afal) en 19584, como se indica en el texto "Arte Fotográfico" en la web del Centro Virtual Cervantes ${ }^{5}$. Sin embargo treinta años antes la Revista Fotográfica de Barcelona ha-

1 Newhall, 2002: 300.

2 FONTCUBERTA, 2008: 14.

3 López Yepes (editor), 2004: t. ${ }^{\circ}$ I, 69.

${ }^{4}$ El Anuario Afal de 1958 es el cuarto en la historia de la fotografía española, editado veinte años después del término de la guerra civil.

${ }^{5}$ Centro Virtual Cervantes (2013). El papel de la fotografia. Afal. Introducción.

http://cvc.cervantes.es/artes/fotografia/papel_foto/afal/introduccion.htm [Consulta: 25 marzo de 2013] 
bía patrocinado el primer Anuario Fotográfico Español ${ }^{6}$, cuyo propósito fue dar a conocer las mejores obras de los pictorialistas. La publicación coincidió con la edición del catálogo del XX Salón Internacional de Fotografía organizado en París por la Societé Française de Photographie 7 , en el que participaron 48 autores y entre ellos dos españoles: José Ortiz Echagüe con la obra Labriego castellano, y el Conde de la Ventosa con Vieja iglesia y mujeres.

La actividad fotográfica en la posguerra se desarrolló en torno a las sociedades, especialmente a la Agrupación Fotográfica de Catalunya en Barcelona y a la Real Sociedad Fotográfica de Madrid $^{8}$. La mayoría de las asociaciones contaron con boletines informativos, y la sociedad madrileña publicó la revista La Fotografía entre 1900 y 1914, dirigida por Antonio Cánovas del Castillo y Vallejo (Kaulak), que en 1904 llegó a tirar 3.000 ejemplares9. La Sociedad Fotográfica de Madrid creó después la revista Sombras (1944-1954) como órgano de difusión y plataforma de las creaciones y actividades de sus miembros, y dentro de ese período (1946 y 1948) se publicaron los dos anuarios que analizamos. En el resto del país la actividad en las asociaciones y entidades culturales fue reducida pero constante, con nueve grupos censados en Sombras en 1946: cuatro en Cataluña y el resto en Madrid, Elche, Valencia, Zaragoza y Écija, más otras seis asociaciones en proceso de creación: Andalucía, Asturias, Guipúzcoa, Orihuela, Novelda y Vigo. Dos años después, en 1948, se sumaron cinco secciones de fotografía vinculadas a centros excursionistas.

En la historiografía sobre la materia son escasas las referencias a la década de los cuarenta y prácticamente nulas a los anuarios publicados por Sombras, con excepción de Mónica Carabias ${ }^{10}$. Esa década fue "traumática y oscura", como indica Carlos Cánovas, porque la actividad de los fotógrafos con talento fue silenciada y porque no se daban las condiciones mínimas para relanzar la fotografía ${ }^{11}$.

Es objeto de este artículo analizar los contenidos de ambos anuarios, teniendo en cuenta el antecedente de 1924, con el fin de cubrir la falta de información a la que aluden los historiadores. Se pretende por tanto investigar sobre los autores y sus obras, las asociaciones y las empresas, para contribuir a un mayor y más profundo conocimiento de la fotografía española en la posguerra.

La metodología empleada, tras la revisión de la bibliografía, ha sido la elaboración de una base de datos para el vaciado completo de los contenidos de los anuarios, con el fin de obtener los nombres de los autores, los títulos de las obras, así como los profesionales dedicados a la fotografía. Posteriormente se han analizado las obras y se ha realizado el estudio comparativo entre anuarios para obtener los resultados que se presentan en las tablas elaboradas al efecto. Se ha llevado a cabo también la selección y reproducción de las obras que se consideran representativas para incluirlas como ilustración al texto. Finalmente se han añadido dos anexos con los fotógrafos del Anuario de 1924 y los profesionales censados en España entre 1946 y 1948.

\section{El primer anuario fotográfico español}

La Revista Fotográfica ${ }^{12}$ de Barcelona patrocinó en 1924 el Anuario de la Fotografía Española, editado por la empresa Pal-Las S.A., en cuya portada se indicaba: "Primero de su publica-

${ }^{6}$ Anuario Fotográfico Español. Barcelona: Pal-Las. Revista Fotográfica, 1924.

7 XX Salon International de Photographie. París: Braun \& Cíe. Éditeurs, 1925.

${ }^{8}$ Martín López y MuÑoz García, 2004.

9 Molinero Cardenal, 2001: 89.

10 Carabias, 2011: 53-54.

11 CÁnOvas, 1992: 11.

12 Revista Fotográfica fue fundada por Vincens Caldés Arús en Barcelona, propietario del comercio fotográfico del mismo nombre. Salió en julio de 1923 y cerró en junio de 1925. Se publicaron 21 números y la información era prioritariamente de carácter técnico, con artículos traducidos de Leancourt, Ch. Duvivier, Otto Siebert y G. Cher. Las ilustraciones eran escasas, con una media de dos fotos por ejemplar.

Arch. esp. arte, LXXXVII, 348, OCTUBRE-DICIEMBRE 2014, 383-400

ISSN: 0004-0428, eISSN: 1988-8511, doi: 10.3989/aearte.2014.24 
ción”. El modelo de referencia en cuanto a la forma (tamaño y diseño) fue el anuario británico Photograms of the year. Los criterios de selección de los 50 autores y obras (anexo 1; figs. 2 y 3) reproducidas en las 64 páginas del libro se explican en el editorial, dando preferencia a los temas inéditos. Su contenido se estructuró en cuatro partes: Introducción, Índice de autores y obras, Fotografías seleccionadas y Publicidad (9 páginas de 64), con anuncios de las principales firmas de cámaras, óptica, mecánica, películas y papeles: Voigtlander, Cappelli, Perutz, Agfa, Eastman, Bayer y Reitzschel. El objetivo del Anuario quedó expuesto en la introducción (sin firma) incluida la crítica a la técnica de los autores:

El propósito inicial, el que nos impulsó a emprender el esfuerzo, fue el de dar a conocer las mejores obras de artistas españoles, obtenidas por medio de la fotografía... Se halla en la mayoría de las obras fotográficas de autores españoles una gran dosis de ingenio, de buen gusto, de inspiración. Sin ser su técnica superior a la de los franceses e italianos, ni llegar al grado de perfección de los americanos, de los alemanes ni de los rusos, tienen en cambio sus concepciones una belleza, una vida y una fuerza de humanidad.

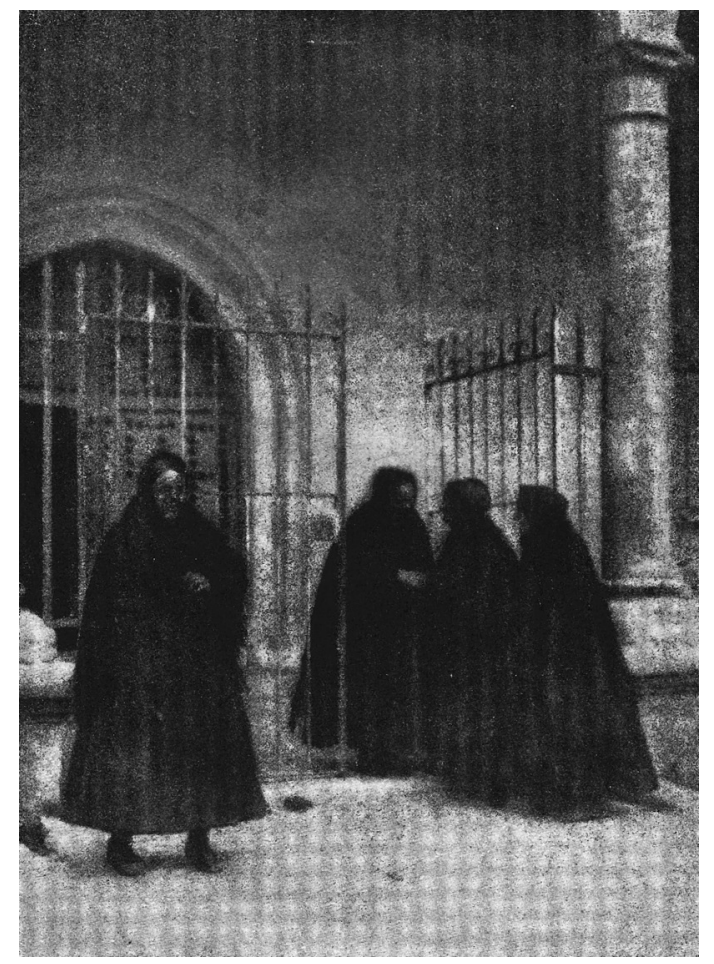

Fig. 2. Francisco Andrada. Beatas. Anuario de 1924.

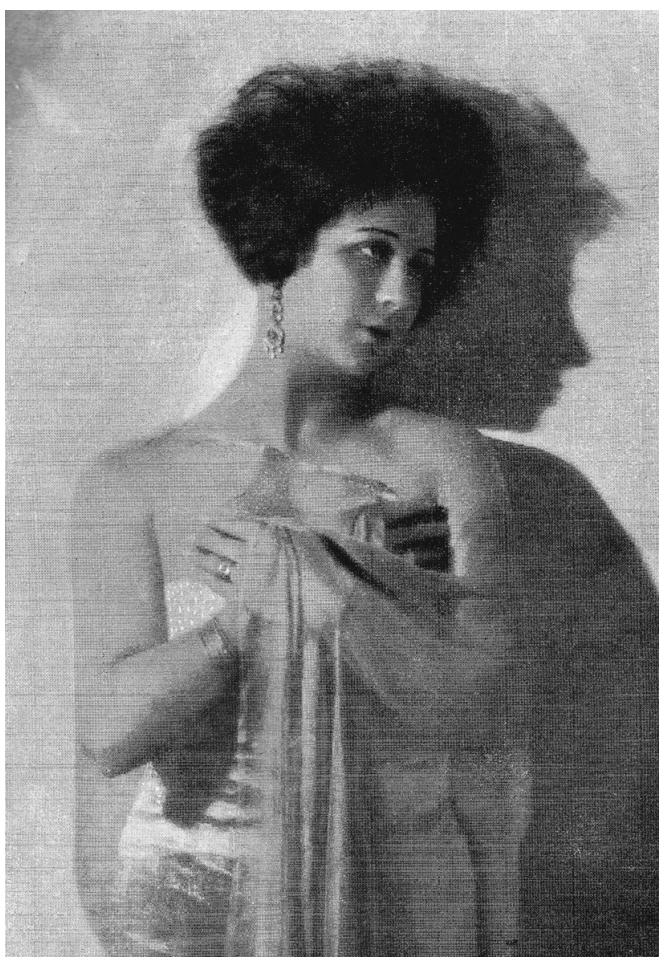

Fig. 3. José Massana. Estudio. Anuario de 1924.

Las observaciones del editor en el preámbulo nos advierten que "los concursos escaseaban, las exposiciones eran mínimas y la organización de salones prácticamente imposible". Las fotos seleccionadas respondían a la corriente pictorialista dominante, realizadas en buena parte por autores de prestigio, entre ellos: Francisco Andrada, Rafael Areñas, Antoni Arissa, Vicente Mar- 
tínez Sanz, Josep Massana, Vicente Novella, Ortiz Echagüe, Eduardo Susanna o Joaquín Vilatobá. Por lo que respecta a la temática, se establecieron cuatro apartados: Paisajes, Retratos, Escenas de costumbres y Bodegones, con equilibro en cuanto a la cantidad. Es significativo el hecho de que se hiciera una llamada en la portadilla a los autores españoles, y a los extranjeros afincados en el país, con objeto de preparar el anuario del año 1925, que finalmente solo quedó en proyecto.

\section{La revista Sombras y los anuarios}

Apenas un sexenio después del final de la guerra civil, con una economía inexistente y en un momento político de incertidumbre por las posibles consecuencias tras la derrota alemana en la contienda mundial, salió la revista de fotografía Sombras, la única en la especialidad y por tanto el escaparate de la creación en aquel momento, aunque según Horacio Fernández el papel de las revistas fue realizar "Evocaciones de pinturas o grabados compuestos a base de contornos difuminados, retoques y atmósferas nubladas"13. López Mondéjar indica en su Historia de la Fotografía Española que el arte de posguerra, tras la victoria militar de 1939, era concebido como "Algo meramente ceremonial, puesto al servicio del Estado y del Imperio"14.

Sombras fue fundada por la Real Sociedad Fotográfica, entidad creada en Madrid en 1899. Mónica Carabias ${ }^{15}$ establece tres etapas en el desarrollo de la publicación: la primera entre junio de 1944 y octubre de 1946 bajo la dirección de su fundador Domingo de Luis, la segunda hasta noviembre de 1949 coordinada por Francisco Velilla, y la tercera con límite en noviembre de 1954 con José Ventura y Cristóbal Batalla al frente. Vicente Castedo, vicepresidente de la institución en 1944, se encargo del editorial de presentación, en el que se indicaba que la revista era "Para cuantos practican el noble deporte de la fotografía y para aquellos que hacen de este arte su vivir cotidiano"16:

Pocas veces pudo decirse de una publicación tan apropiadamente que viene a llenar un vacío, por mucho que el abuso haya disminuido el valor de la frase. Lo demuestra su añorada necesidad, por no existir otra análoga en España; su valor, por igualarse a las más preciadas extranjeras; su programa completo en la técnica y en la literatura; sus firmas prestigiosas, ante las cuales la mía se empequeñece, y sus iniciativas, propósitos y esfuerzos financieros para alcanzar y consolidar los resultados.

Mantener una publicación especializada en fotografía durante aquella década fue todo un reto, superado con la cuidada presentación (papel especial e impresión en huecograbado) y con la participación de la mayoría de los autores creativos. Los dos últimos años coincidió con Arte Fotográfico, fundada en 1952 por Diego Gálvez, quien cedió la propiedad a Ignacio Barceló.

En el período de edición de Sombras se publicaron, en 1946 y 1948, los dos anuarios a que ya nos hemos referido, y que coincidieron con la creación de la mítica agencia Magnum en Estados Unidos el año 1947 por Cartier-Bresson, Rodger, Capa y Seymour ${ }^{17}$. Los objetivos generales fueron presentar el trabajo de los autores y sus obras, así como las novedades técnicas, informar a los profesionales y aficionados sobre las agrupaciones y sociedades, y censar las empresas en activo. En el análisis de los contenidos se advierten otros propósitos como la difusión de la publicación entre los profesionales y aficionados incluidos en el libro. La financiación

\footnotetext{
13 FERnÁndeZ, H., 1996: 17.

14 LÓPEZ MONDÉJAR, 1997: 178.

15 CARABIAS, 2008: 15-22.

16 SÁNCHEZ Vigil, 2007: 44.

17 Molinero Cardenal, 2001: 330-335.
}

Arch. esp. arte, LXXXVII, 348, OCTUBRE-DICIEMBRE 2014, 383-400

ISSN: 0004-0428, eISSN: 1988-8511, doi: 10.3989/aearte.2014.24 
se consiguió fundamentalmente con la publicidad de tres firmas de prestigio: Kodak, Gevaert y Valca, más la del resto de proveedores con menor peso específico.

Los fotógrafos censados en 1946 fueron 1.599 (gráfico 1), con un ligero descenso a 1.588 en 1948. El 25\% de las empresas (400) se encontraban en Madrid y Barcelona, con claro predominio de esta última; 14 provincias, incluidas Melilla y las localidades del Protectorado, sumaban el 35\% (600 empresas), y en las 37 provincias restantes se distribuía el resto.

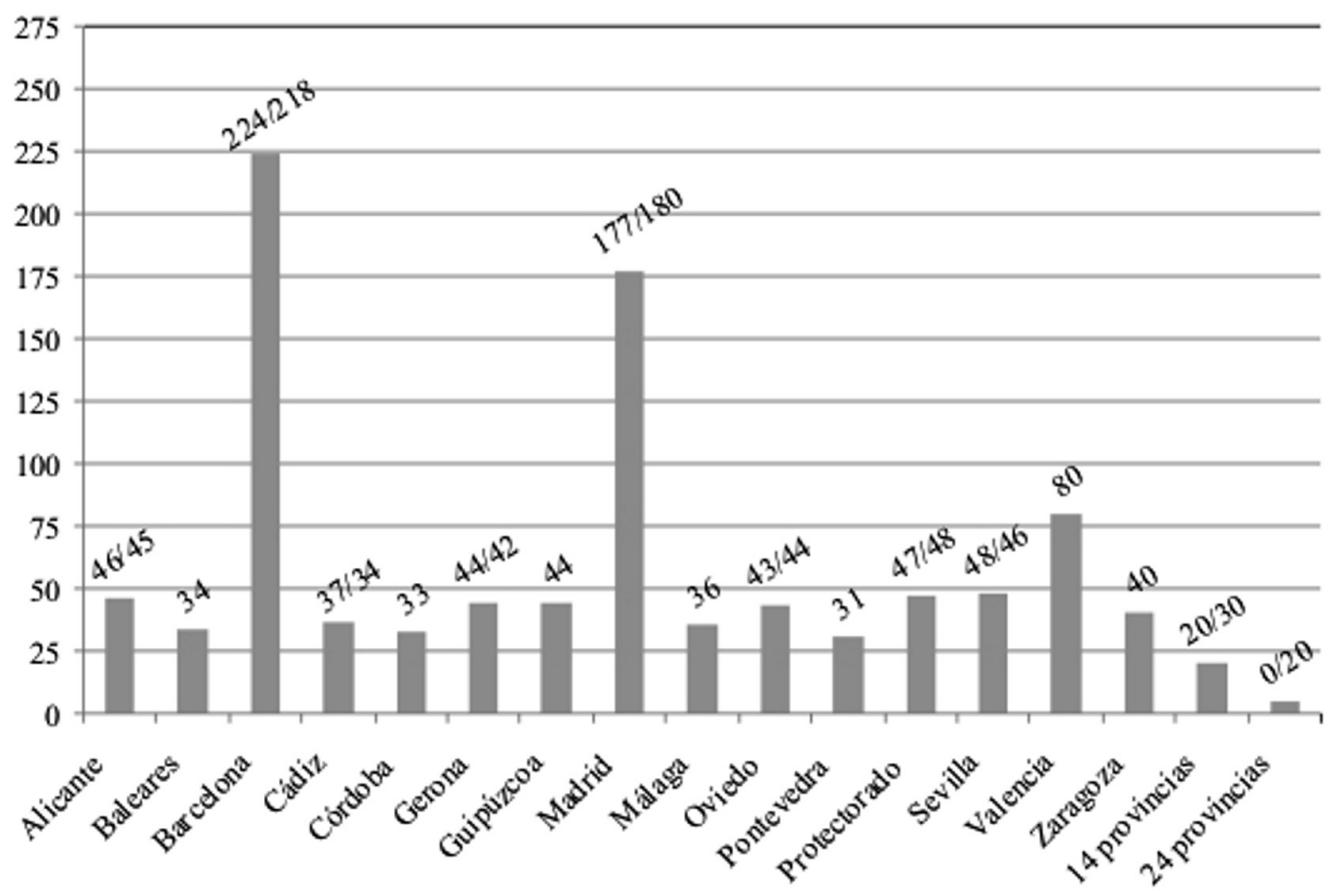

Gráfico 1. Fotógrafos censados en los anuarios de Sombras (1946/1948).

\section{Anuario de 1946}

El anuario de 1946 fue dirigido por el ingeniero militar Eduardo Susanna Almaraz, redactor de la revista Sombras y vicepresidente de la Real Sociedad Fotográfica de Madrid, mientras que Domingo de Luis, fundador de la revista fue el editor. Susanna, cuya obra figuró entre las elegidas para el anuario de 1924, se había formado en el pictorialismo, había experimentado todos los procedimientos pigmentarios desde los años veinte, y había creado el taller Construcciones Fotográficas para la reparación de aparatos y la adaptación de lentes en las cámaras Leica y Contax.

El anuario se concibió como "Una enciclopedia que ha de filtrar cuidadosamente todas las novedades del año, incorporando todo lo que haya de útil". Con este concepto Susanna se refería a los procedimientos fotográficos y sus actividades (teoría y práctica), y a la concepción y realización de la obra (circunstancias del artista). 
Se encuadernó en tela azul estampada en oro, dividido en tres partes: textos, ilustraciones, y listados de suscriptores, profesionales y agrupaciones fotográficas. Los textos se abrían con el prólogo, seguido de tres capítulos técnicos: el primero sobre el color (tres artículos), el segundo sobre el positivado y los procedimientos (ocho artículos), y el tercero sobre las novedades y datos prácticos (4 artículos). En el prólogo se reivindicaba el carácter artístico de la fotografía:

Si la fotografía no es un arte clásico, es por lo menos el medio de expresión de muchos artistas. Nadie puede negar la posibilidad de producir fotográficamente una obra bella. La misma cámara, con el mismo objetivo y el mismo material y procedimientos, pueden dar lugar, según las manos que los manejen, a resultados totalmente diferentes, aún con idéntico modelo e idéntico tema.

Se seleccionaron 40 fotos de 34 autores (tabla 1), reproducidas en 32 páginas, con un extenso comentario para cada una de ellas firmado por "Cromófilo", más 6 imágenes de aficionados (Miguel Herrero, Elisenda, Caamaño, Castillo, Lucy Esquerdo y J. Álvarez) que ya habían sido publicadas y comentadas en la revista. Todas las obras reflejan la corriente imperante, definida como "tardopictorialismo" y representadas por los clásicos de los años veinte y treinta, con excepción de Aurelio Grasa formado en el fotoperiodismo y vinculado a las vanguardias tras viajar a París en los años veinte, donde contactó con los autores de la corriente Nueva Objetividad, publicando en National Geographic Magazine y la Revue Moderne.

Cuatro de los autores que habían publicado en el anuario de 1924 repitieron la experiencia: Eduardo Susanna, Francisco Andrada, el conde de la Ventosa y José Ortiz Echagüe, de cuya fotografía se dice: "No haría falta la firma para saber que Novia sin sotana es un obra de Ortiz Echagüe. Hace muchos años que este maestro indiscutible de la fotografía creó un estilo inimitable y permanece fiel a él a través de toda su magnífica obra de fotografías de España”.

Los criterios de selección son cuestionables, ya que se incluyen dos obras que datamos antes de la guerra civil: la primera, titulada En el ruedo, de Manuel Cervera, tomada en la corrida de

Tabla 1. Autores del anuario Sombras de 1946.

\begin{tabular}{|l|l|}
\hline \multicolumn{1}{|c|}{ Autor } & \multicolumn{1}{c|}{ Titulo } \\
\hline Alfonso & Jacinto Benavente \\
\hline Andrada, F. & Albercaza \\
\hline Asensi, L. & Barquitos \\
\hline Bau, Joaquín & Aceite \\
\hline Bonoso de Arcos & Holandesa \\
\hline Campañá, Antoni & Y vinieron \\
\hline Carbolleu, C. & Estampa marroquí \\
\hline Carreras Soley, D. & Fluvius \\
\hline Cartajena (sic) & Mariano Benlliure \\
\hline Cervera, Manuel & En el ruedo \\
\hline Corbella, Luis & Estudio \\
\hline Franzen & Retrato \\
\hline Gálvez, Diego & Amanecer de reyes \\
\hline Garay, Daniel & Estudio \\
\hline Gonzaléz Aguilar & Sombras transparentes \\
\hline Grasa, Aurelio & Reflejo \\
\hline Irurzun, Pedro M. & Espigas \\
\hline
\end{tabular}

\begin{tabular}{|l|l|}
\hline \multicolumn{1}{|c|}{ Autor } & \multicolumn{1}{c|}{ Titulo } \\
\hline Jiménez, Julio & Muñecas \\
\hline Lozano, J. & En el tendido \\
\hline Macías Rodríguez, P. & La risa del zagal \\
\hline Manuel & Estudio \\
\hline Mora Carbonell, F. & Días y años \\
\hline Núñez, J. & Desolación \\
\hline Ollé, Antonio & Borrasca \\
\hline Ortiz Echagüe & Novia ansotana \\
\hline Pajares, A. & Los cuatro postes \\
\hline Palau, Antonio & Luz solar \\
\hline Pla Janini, J. & Plafón decorativo \\
\hline Sánchez Ors & En Semana Santa \\
\hline Soriana, Marqués de & La cosecha \\
\hline Susanna, Eduardo & Moza de cántaros \\
\hline Tinoco, José & Negro y blanco \\
\hline Vallmitjana, A. & Vejer de la Frontera \\
\hline Ventosa, Conde & Bruma \\
\hline
\end{tabular}

Arch. esp. arte, LXXXVII, 348, OCTUBRE-DICIEMBRE 2014, 383-400

ISSN: 0004-0428, eISSN: 1988-8511, doi: 10.3989/aearte.2014.24 
toros de Toledo en 1918, y la segunda el retrato de Jacinto Benavente realizado a mediados de los veinte por Alfonso en su estudio de la calle Fuencarral. Puede interpretarse la inclusión de estas dos fotografías como un guiño a los clásicos, e incluso como reivindicación de esto autores, ya que Alfonso había sido depurado al término de la guerra por su actividad fotoperiodística.

Del análisis de los contenidos resultan cuatro temas generales: Retratos (19 fotografías), Paisajes y vistas (7), Escenas y costumbres (10) y Composiciones (4). Prácticamente la mitad de las imágenes son retratos, mientras que escasean las composiciones, características de la vanguardia en el período de entreguerras. Se observa una miscelánea de obras, autores y estilos, reflejo de un momento de transición, con fuertes reminiscencias del pasado y del clasicismo, muy obvio en los retratos de estudio, como en los casos de Luis Corbella o Daniel Garay (fig. 4), que en el titulado Estudio imita la pintura de Julio Romero de Torres, incluida la guitarra española. Son clásicos también los tipos populares ataviados con trajes regionales (Ortiz Echagüe, Susanna, Francisco Andrada y Bonoso de Arcos) y las escenas costumbristas (Mora Carbonell), y no se comprende, por su simpleza, la selección del retrato de Mariano Benlliure realizado por Cartajena (sic).

Los paisajes se resuelven con encuadres convencionales y una estética desfasada. La obra Borrasca de Antonio Ollé Pinell, autor de la Enciclopedia de la Fotografia, es la de peor calidad, y el resto es mediocre, con excepción de Reflejo, de Aurelio Grasa, y Bruma del Conde de la Ventosa (fig. 5). En cuanto a las composiciones, la obra más destacada por la dificultad técnica es la titulada Plafón decorativo de Pla Janini; y rompen la monotonía las obras de Sánchez Ors con un contrapicado de una escena de Semana Santa y Amanecer de Reyes, de Diego Gálvez, muy vanguardista y con gran dominio de la luz y las sombras (fig. 6). El soplo de aire fresco está en las fotografías de los aficionados, de peor calidad técnica y con encuadres menos trabajados, pero más documentales y ricas en detalles.

Por lo que respecta a las agrupaciones y sociedades de las que formaban parte amateurs y profesionales, figuran nueve, seis de ellas dedicadas exclusivamente a la fotografía, más tres secciones de entidades culturales. Cuatro se encontraban en Cataluña (dos en Barcelona, una en Igualada y la cuarta en Villanueva y la Geltrú), más las de Madrid, Zaragoza, Valencia, Elche y Ecija. Asimismo, se indica que se encontraban en formación la Agrupación Fotográfica Andaluza y Asturiana, más dos sociedades en Orihuela y Novelda (tabla 2).

Tabla 2. Anuario Sombras. Sociedades y Secciones Fotográficas en 1946.

\begin{tabular}{|l|l|l|}
\hline \multicolumn{1}{|c|}{ Agrupación } & \multicolumn{1}{c|}{ Localidad } & \multicolumn{1}{c|}{ Presidente } \\
\hline Fotográfica de Cataluña & Barcelona (Duque de Victoria 14) & Manuel Ballespi \\
\hline Fotográfica de Igualada & Igualada (Barcelona, San Jaime 6) & Pedro Borrás \\
\hline Foto Club de Valencia & Valencia (Paz 26) & Francisco Caps Dais \\
\hline Peña Fotográfica Elche & Elche (Alicante) & Gabriel R. Chorro \\
\hline Real Sociedad Fotográfica & Madrid (Príncipe 16) & Conde de la Ventosa \\
\hline Fotográfica de Zaragoza & Zaragoza (Plaza de Sas 7) & Lorenzo Almarza \\
\hline \multicolumn{1}{|c|}{ Secciones } & \multicolumn{1}{|c|}{ Localidad } & \multicolumn{1}{c|}{ Presidente } \\
\hline \multicolumn{1}{|c|}{ Villanueva y Geltrú } & Barcelona & Alfonso Foradada Coll \\
\hline Centro Exc. de Cataluña & Barcelona (Plaza del Pino 5) & Juan Pi \\
\hline Club Artístico de Écija & Sevilla & Eloy Herrera Pineda \\
\hline
\end{tabular}




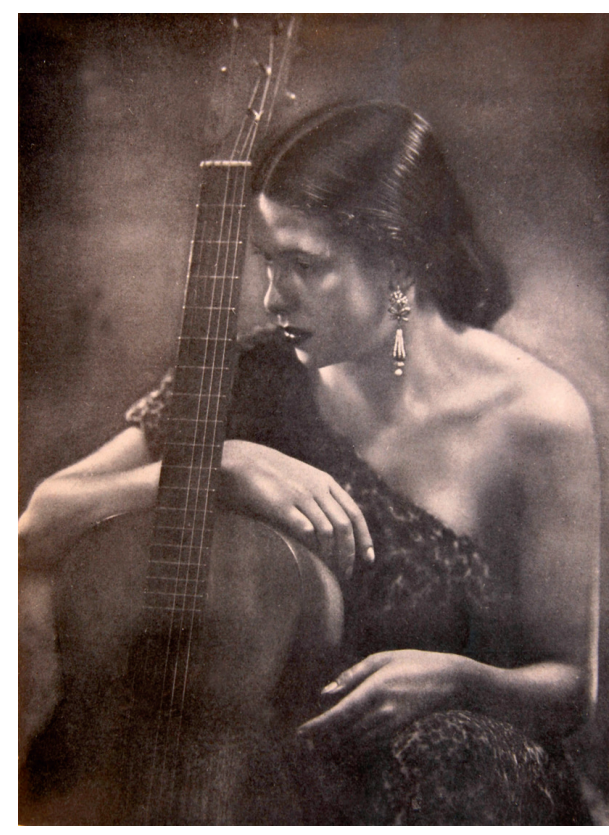

Fig. 4. Daniel Garay. Retrato. Anuario Sombras, 1946.

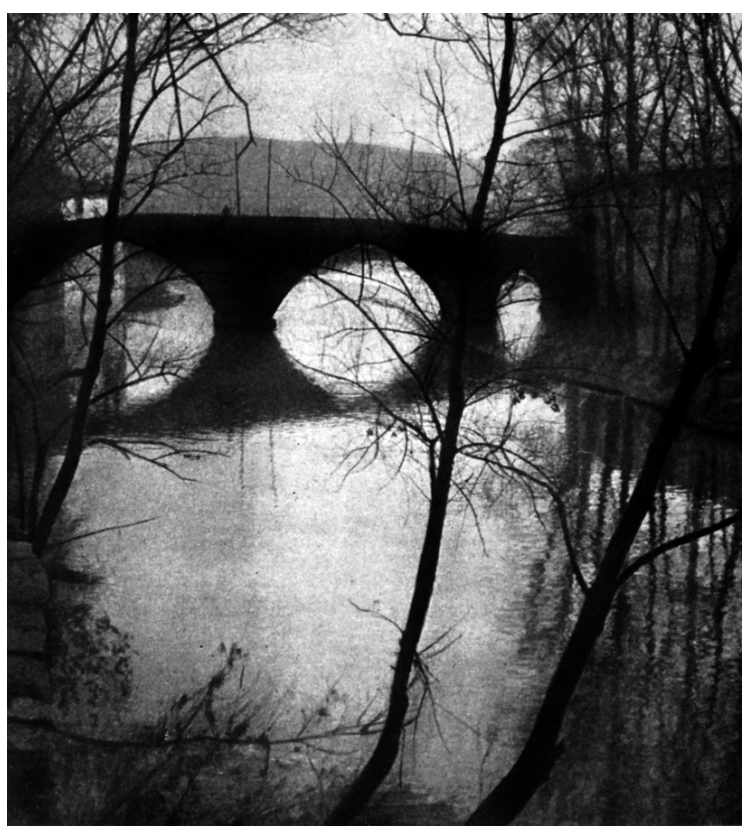

Fig. 5. Conde de la Ventosa. Bruma. Anuario de 1946.

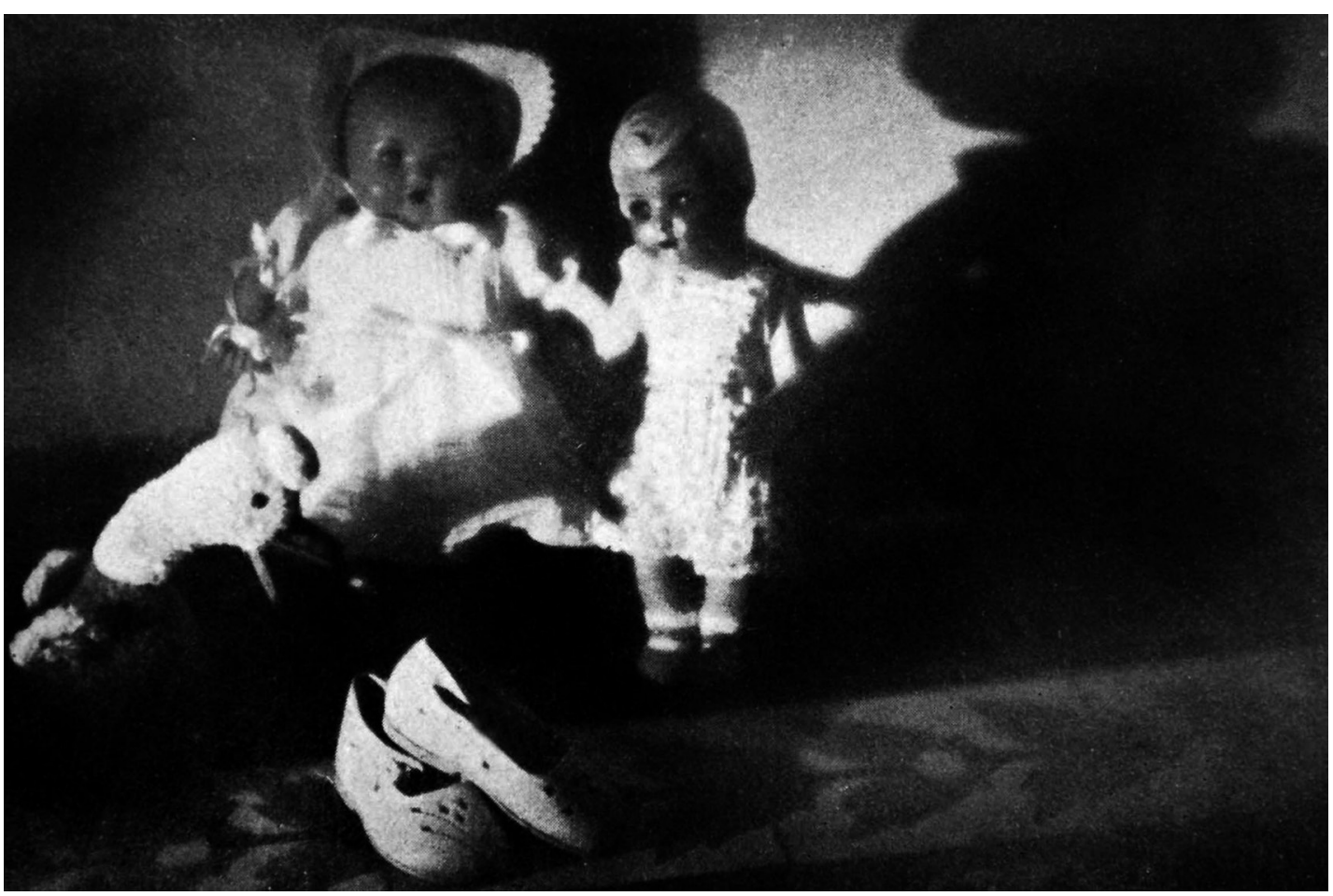

Fig. 6. Diego Gálvez. Amanecer de Reyes. Anuario de 1946.

Arch. esp. arte, LXXXVII, 348, OCTUBRE-DICIEMBRE 2014, 383-400 ISSN: 0004-0428, eISSN: 1988-8511, doi: 10.3989/aearte.2014.24 
La relación de suscriptores a la revista nos permite conocer a gran parte de los profesionales en activo. Se catalogaron 1.599 fotógrafos (anexo 2), con indicación del nombre, localidad y dirección. De ellos 139 pertenecían a Barcelona y 155 a Madrid. Esta relación es de gran interés, ya que el Anuario les atribuye una categoría (redactor y colaboradores de Sombras, expositor nacional y/o internacional, miembro de agrupaciones o sociedades).

La referencia a los proveedores es clave para el conocimiento de la industria y el comercio de fotografía en la posguerra civil española. Tras un largo período de inactividad se produjo un resurgir lento debido a la escasa importación de productos y a la situación económica del país. En 1946 había en España más de seiscientos establecimientos entre fabricantes, distribuidores, comercios y laboratorios. Algunos de estos proveedores aparecen de manera destacada y con publicidad, de lo que se deduce una mejor situación económica que el resto: Casa Sánchez (Alicante); Luis Balta, Campañá, Gaspar Mampel, Soteres y Torras (Barcelona); Espiga (Bilbao); Casa Bosch (Gerona); Aeolian, Athia, Valentín Fernández López, Gan, Román García, Jiménez, López Elizalde, Braulio López, José Ortiz, Peñalara, Sarralde (Madrid); Foto Moda (Sevilla); Casa Manero (Valencia); Óptica Iris (Valladolid); Foto Club y Casa del Aficionado (Vigo); y Cuevas (Zamora).

\section{Anuario de 1948}

El anuario de 1948 fue editado por Biblis y constó de 172 páginas divididas en tres partes: textos, ilustraciones y relaciones de suscriptores, profesionales, proveedores y asociaciones. El diseño fue muy cuidado, con encuadernación en tela gris estampada en seco en dos colores, azul y rojo, y tres tipos de papel para separar los contenidos: el habitual para los textos, cuché para las ilustraciones y de tono rosado para los listados. No se incluyó presentación o prólogo, tampoco se especificaron los objetivos y los criterios de selección de las imágenes, ni se indicaron los autores de los textos, todos de carácter técnico: positivado artístico (diez procedimientos), fórmulas, productos químicos y tipología de objetivos anastigmáticos.

Se reprodujeron 32 fotografías de 27 autores (una por página a modo de lámina), en buena parte procedentes de los concursos mensuales convocados por Sombras (17 fotos) en varios certámenes: Exposición del Nuevo Club Deportivo de Bilbao, Club Excursionista de Gracia, Salón Graciense de Arte Fotográfico y Salón del Foto Club Valencia. Al contrario que en 1946, se apostó por nuevos creadores, ya que tan solo dos autores eran conocidos por su actividad: Toribio Noaín, del que se seleccionó un retrato, y el paisajista Marqués de Santa María del Villar. Carmen Guerra fue la única mujer en los anuarios, de la que se seleccionan dos obras: la primera una toma nocturna de la Plaza Mayor de Salamanca, destacable por las sombras y por el grano, y la segunda una feria de ganado, más convencional en el encuadre (tabla 3).

En cuanto a la temática, presenta cuatro apartados: Retratos (3), Paisajes y vistas (16), Composiciones (6) y Escenas y costumbres (7). La estética responde, al igual que en 1946, al pictorialismo tardío, con escenas rebuscadas y manidas. Se observan algunas modificaciones como la desaparición de los trajes regionales en los retratos, el uso del contraluz como elemento destacable, agudizando las obras, y la primacía de los bodegones de frutas y hortalizas en las composiciones.

Los paisajes, tanto los naturales como los rurales y urbanos, responden al tópico, sin nuevas aportaciones creativas, y los pocos retratos son de escaso interés. De las composiciones destaca la titulada En el estudio, de Felipe Torres (fig. 7), muy vanguardista por el encuadre de los objetos seleccionados (chinchetas) y con influencias de la Nueva Objetividad. De mayor fuerza emocional, pero claramente pictorialistas, son Penitencia de Andrés Oliva (fig. 8) e Infancia de Amadeo Pujol Moragas, con un guiño a la revista Sombras (fig. 9). En cuanto a los retratos, es destacable el titulado Marinero de Enrique Carreras (fig. 10), de impecable composición. 
Tabla 3. Autores del anuario Sombras de 1948.

\begin{tabular}{|l|l|}
\hline \multicolumn{1}{|c|}{ Autor } & \multicolumn{1}{c|}{ Título } \\
\hline Bermejo, Moisés & Nieve \\
\hline Carreras, Enrique & Marinera \\
\hline Cisneros & C/del Arco (Huercal) \\
\hline Estany Vallestín, J. & Nubes de otoño \\
\hline Fatás Ojuel, G. & El último surco \\
\hline Folch Jou, G. & Aspas \\
\hline Foradada, Alfonso & Clausura \\
\hline Guerra Velasco, C. & Feria en Pontevedra \\
\hline Guerra Velasco, C. & Pl. Mayor Salamanca \\
\hline Mejón, Luis & Nocturno en el Prado \\
\hline Merlo Delgado, A. & Aspas \\
\hline Noaín, Toribio & Chomin \\
\hline Oliva, Andrés & Penitencia \\
\hline Panero Pérez, José & Barbechera \\
\hline Pascual Raga, F. & Almoraira la blanca \\
\hline Pastor, Javier & Guindola \\
\hline
\end{tabular}

\begin{tabular}{|l|l|}
\hline \multicolumn{1}{|c|}{ Autor } & \multicolumn{1}{c|}{ Título } \\
\hline Pujol Moragas, A. & Abstracción \\
\hline Pujol Moragas, A. & Sabor de campo \\
\hline Renard, L. & Ramco \\
\hline Rivas Moret, Ant. & Caracol \\
\hline Romero-Rato & Contraluz \\
\hline Rosa Casaco, Ant. & Últimas noticias \\
\hline Rosa Casaco, Ant. & Sede matutina \\
\hline Sánchez-Mata, J.C. & Rochano Manchego \\
\hline Sta. María del Villar & Picos de Europa \\
\hline Sierra Calvo & Bucólica \\
\hline Sierra Calvo & Sinfonía \\
\hline Torres, Felipe & En el estudio \\
\hline Torres, Felipe & Cresterías Monterrey \\
\hline Torres Romero, F & Uvas y manzanas \\
\hline Tubau, Miguel & Carros \\
\hline Valls Más, J. & Luz y sombras \\
\hline
\end{tabular}

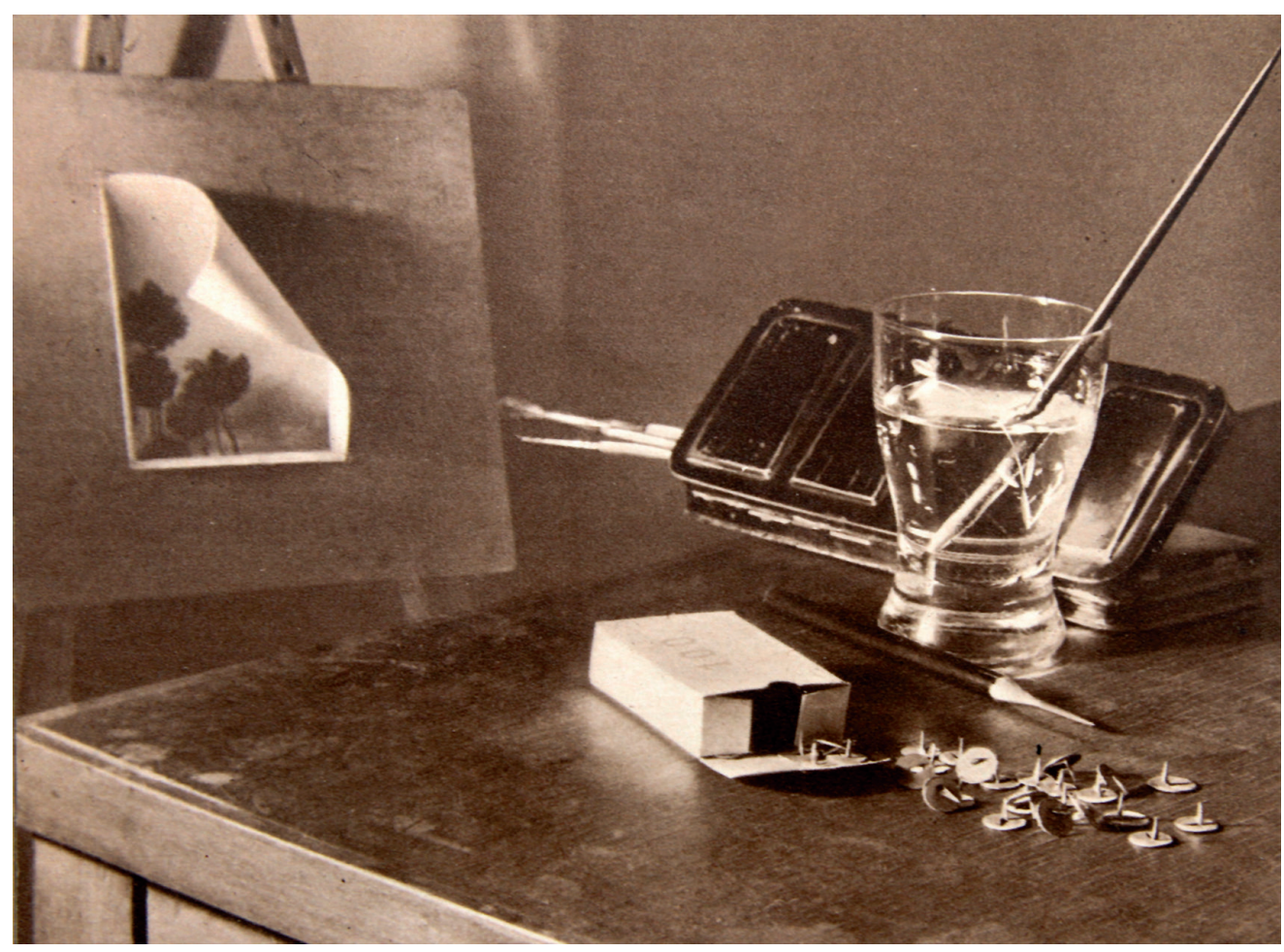

Fig. 7. Felipe Torres. En el estudio. Anuario de 1948.

Arch. esp. arte, LXXXVII, 348, OCTUBRE-DICIEMBRE 2014, 383-400 ISSN: 0004-0428, eISSN: 1988-8511, doi: 10.3989/aearte.2014.24 


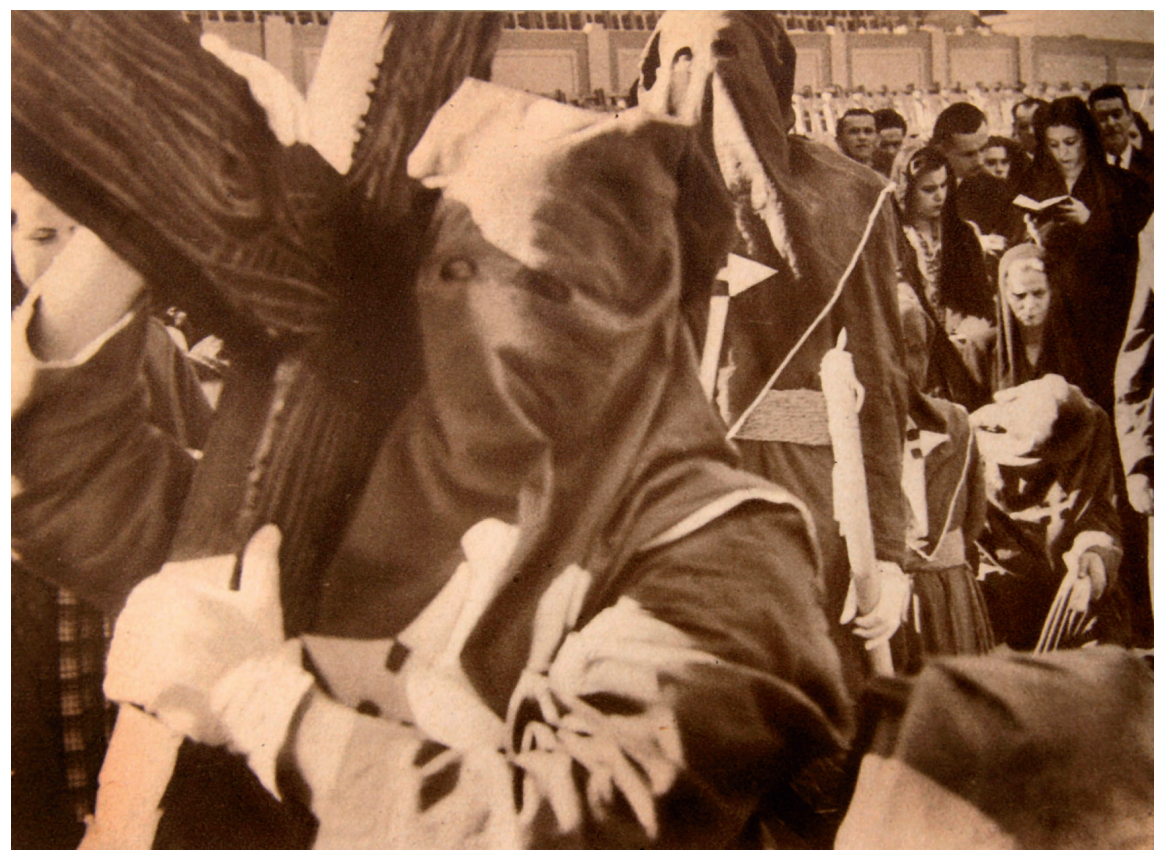

Fig. 8. Andrés Oliva. Penitencia. Anuario de 1948.

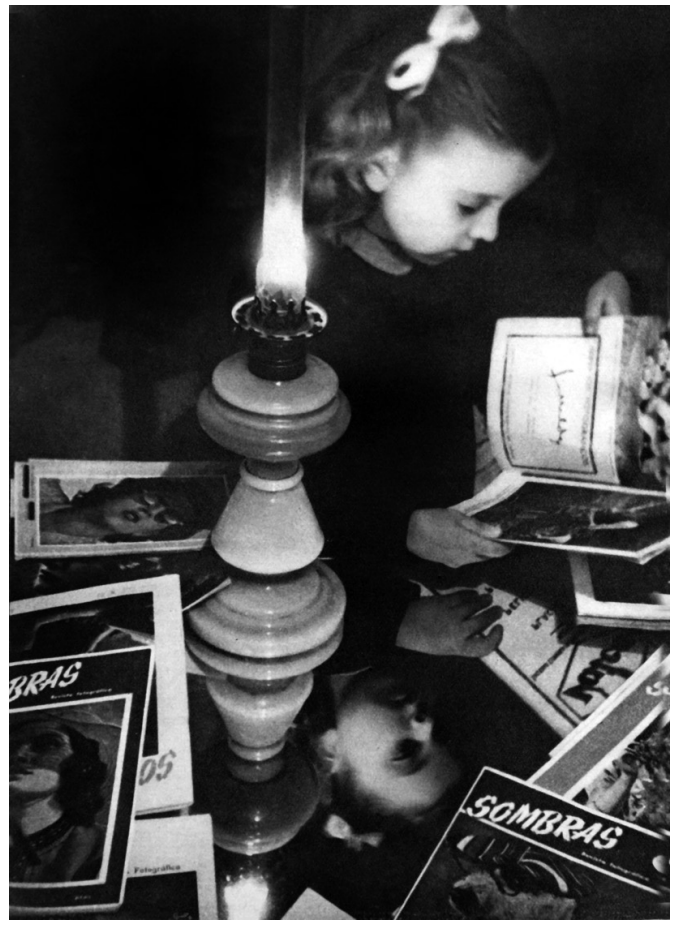

Fig. 9. Amadeo Pujol Moragas. Infancia. Anuario Sombras, 1948.

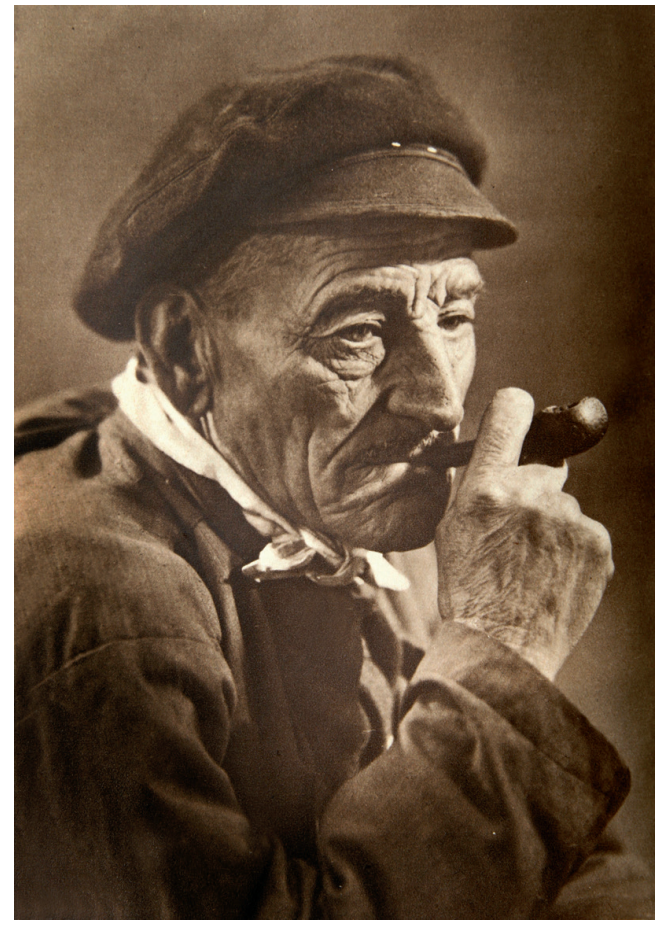

Fig. 10. Enrique Carreras. Marinera. Anuario de 1948.

Arch. esp. arte, LXXXVII, 348, OCTUBRE-DICIEMBRE 2014, 383-400 ISSN: 0004-0428, eISSN: 1988-8511, doi: 10.3989/aearte.2014.24 
Por lo que respecta a las sociedades y agrupaciones (tabla 4), las referencias en el anuario son 14, seis dedicadas exclusivamente a la fotografía y ocho secciones de entidades culturales con diversas actividades, principalmente el excursionismo, tan de moda desde el último tercio del siglo XIX. El papel de estos grupos, vinculados en su mayoría a la investigación científica, fue crucial para el desarrollo de la fotografía en todos los sentidos, no solo por su práctica sino por su aplicación a la docencia y a la divulgación en materias como la medicina, la arqueología o la historia.

Tabla 4. Sociedades y Secciones Fotográficas en el anuario Sombras de 1948.

\begin{tabular}{|l|l|l|}
\hline \multicolumn{1}{|c|}{ Agrupación } & \multicolumn{1}{c|}{ Localidad } & \multicolumn{1}{c|}{ Presidente } \\
\hline Fotográfica de Cataluña & Barcelona (Duque de Victoria 14) & Félix Fornells Puig \\
\hline Fotográfica de Igualada & Igualada (Barcelona, San Jaime 6) & José Bisbal \\
\hline Foto Club de Valencia & Valencia (Paz 26) & Vicente Peydró \\
\hline Peña Fotográfica Elche & Elche (Alicante) & Gabriel R. Chorro \\
\hline Real Sociedad Fotográfica & Madrid (Príncipe 16) & Conde de la Ventosa \\
\hline Fotográfica de Zaragoza & Zaragoza (Plaza de Sas 7) & Lorenzo Almarza \\
\hline \multicolumn{1}{|c|}{ Secciones } & \multicolumn{1}{|c|}{ Localidad } & \multicolumn{1}{c|}{ Presidente } \\
\hline Sociedad Villanueva y Geltrú & Barcelona & Alfonso Foradada \\
\hline Centro Excursionista Cataluña & Barcelona (Plaza del Pino 5) & Juan Pi \\
\hline Club Artístico de Écija & Sevilla & Eloy Herrera Pineda \\
\hline Soc. Econ. de Amigos del País & Málaga & Andrés Oliva \\
\hline Centro Excursionista del Bagés & Manresa (Barcelona, Urgel, 14) & José María Font \\
\hline Club Deportivo Bilbao & Bilbao (Alcalde Recalde 28) & Cándido Fullaondo \\
\hline Montañeros del Club Celta & Vigo & José Delgado \\
\hline Sociedad Alpinismo Peñalara & Madrid (José Antonio 27) & Ramón González \\
\hline
\end{tabular}

Los suscriptores de la revista en el año 1948 eran 1.906, casi doscientos más que en 1946, lo que garantizaba la financiación. Además de las agrupaciones bibliográficas que adquirían las revistas para las bibliotecas de las instituciones, en la relación figuran profesionales de larga trayectoria y prestigio como Alfonso o Calvache en Madrid, Coyne de Zaragoza o Legorgeu en Vizcaya.

\section{Valoración y conclusiones}

De esta investigación resultan nuevos datos para la fotografía española en la década de los años cuarenta sobre autores, tendencias, obras, asociaciones, industria y técnica, que permiten ir completando el vacío en los estudios. El escaso número de autores seleccionados en los anuarios, así como el de obras reproducidas, refleja un estado de la cuestión paupérrimo que contrasta con los cerca de 1.600 profesionales censados en las dos publicaciones.

La comparativa de los datos ofrece como resultado que el número de obras seleccionadas en el anuario de 1924 fue de 50, superior al de las dos publicaciones de Sombras en la posguerra: 
40 en 1946 y 32 en 1948. Del mismo modo, el número de autores se redujo: 50 en 1924, 34 en 1946 y 27 en 1948, una limitación sólo justificable por la decadencia del país, sumido en las consecuencias de la contienda civil.

Los criterios de selección de autores (61 en total) no quedan claros en ningún caso, y si bien con carácter general se pretende mostrar las creaciones del momento, no se comprende que se incluya más de una obra de cuatro de ellos en el anuario de 1948. Los conocidos pictorialistas, cuyas obras se publicaron en 1946, cedieron el espacio a nuevos fotógrafos.

Entre los anuarios de 1946 y 1948 no se repitió ni un solo autor; para el primero se seleccionó una obra por fotógrafo, mientras que en el segundo se publicaron dos obras de cuatro autores (Carmen Guerra Velasco, Amadeo Pujol Moragas, Antonio Rosa Casaco y Felipe Torres) y una del resto. Con relación al anuario de 1924, cuatro autores repitieron en 1946, los citados Andrada, Ortiz Echagüe, el conde de la Ventosa y Susanna, editor de este último. En 1948 solo aparece un fotógrafo del anuario de 1924, el marqués de Santa María del Villar, con un tema característico de su amplia producción paisajística: Picos de Europa. Tan solo aparece una mujer en 1948, Carmen Guerra Velasco, de la que se publicaron dos obras tomadas en Pontevedra y Salamanca. La noticia de su participación en un concurso de la revista Sombras sobre "Rincones típicos", y su exclusión en el censo de profesionales, la presenta como amateur y confirma la mínima participación de las mujeres en la fotografía.

En cuanto a los contenidos, se advierte un interés por equilibrar los textos con las imágenes, procurando incluir las novedades sobre técnica, procedimientos, óptica y revelados. Hemos establecido cuatro categorías de ilustraciones: Retratos, Paisajes, Composiciones y Escenas costumbristas. En tan solo dos años el criterio cambió en la cantidad, pasando de 19 retratos en 1946 a 3 en 1948, y los paisajes de 7 a 16. Las escenas de costumbres (10 y 7 respectivamente) y las composiciones ( 4 y 6 ) mantuvieron la media. El pictorialismo fue la estética predominante, con ciertas influencias de la vanguardia en las composiciones (casos de Aurelio Grasa o Felipe Torres), pero no así en los retratos y paisajes. La característica general es la representación del tópico, con las excepciones señaladas en el texto.

Los proveedores y comerciantes censados en ese período fueron más de 600, de ellos 76 con sede en Barcelona y 40 en Madrid. Varios profesionales de prestigio, además de tener estudio, abrieron comercio para la venta de material, entre ellos Torres Molina (Granada), Espiga (Bilbao), Campañá (Barcelona) o Beringola (Madrid).

Un aspecto de gran interés, por la información que aporta, es el censo de fotógrafos por provincias con indicación de la localidad y dirección en la que ejercieron su actividad, datos que nos permiten conocer las zonas geográficas con mayor y menor implantación de empresas y, en consecuencia, la producción por zonas. Es fundamental asimismo la información sobre proveedores de material y artículos fotográficos, clave para conocer la industria de posguerra.

\section{BIBLIOGRAFÍA}

Alsina Munné, H., Historia de la fotografía, Barcelona, Producciones Editoriales del Nordeste, 1954.

Cánovas, Carlos, "Entre dos rupturas", en Tiempo de silencio. Panorama de la fotografía española de los años 50 y 60, Barcelona, Fundación La Caixa y Generalitat de Catalunya, 1992.

Carabias, Mónica, "Un fragmento teórico de la memoria fotográfica en la posguerra española. La revista Sombras (1944-1952)", en Lars. Cultura y Ciudad, 2009, n. ${ }^{\circ} 15$, pp. 77-81.

Carabias, Mónica, Sombras, Revista fotográfica española, 1944-1954, Madrid, Pentagraf, 2011.

Fernández, Horacio, "Fotografía en revistas y revistas de fotografía", en Arte moderno y revistas españolas, 1898-1936. Madrid, Museo Centro de Arte Reina Sofía, 1996.

Fernández, Horacio, Variaciones en España. Fotografía y Arte 1900-1980, Madrid, La Fábrica, 2004.

Fontcuberta, Joan (editor), Fotografia. Crisis de historia, Barcelona, Actar, 2002. 
Fontcuberta, Joan, Historias de la fotografía española. Escritos 1977-2004, Barcelona, Gustavo Gili, 2008. López Mondéjar, P., Historia de la fotografía en España, Barcelona, Lunwerg, 1997.

López Yepes, J. (editor), Diccionario Enciclopédico de las Ciencias de la Documentación, “Anuario”, Madrid, Síntesis, 2004.

Martín López, Ana María y Muñoz García, Manuel, Historia de la Real Sociedad Fotográfica. Voluntad de fotógrafos, Segovia, Universidad SEK y RSF, 2004.

McCuley, Anne, "Escribir la historia de la fotografía antes de Newhall", en Newhall, Beaumont, Historia de la fotografia, Barcelona, Gustavo Gili, 2002, pp. 300-314.

Molinero Cardenal, Antonio, El óxido del tiempo. Una posible historia de la fotografía. Barcelona, Omnicon, 2001.

Newhall, Beaumont, Historia de la fotografia, Barcelona, Gustavo Gili, 2002.

Ollé Pinell, Antonio. Enciclopedia de la Fotografia, Barcelona, Omega, 1957

Sánchez Vigil, Juan Miguel, Del daguerrotipo a la Instamatic, Gijón, Trea, 2007.

Sánchez Vigil, Juan Miguel, La fotografía en España, Gijón, Trea, 2013.

Siles González, Luisa, "Sobre la fotografía de vanguardia en España”, en Pérez Bravo, J. (ed.), La vanguardia en España, París, Cric \& Ophrys, 1998.

Sougez, Marie Loup, Historia de la Fotografía, Madrid, Cátedra, 2004.

Sougez, Marie Loup; García Felguera, María de los Santos; Pérez Gallardo, Helena; Vega, Carmelo, Historia general de la fotografia, Madrid, Cátedra, 2007.

Torres Díaz, Francisco, Crónica de un siglo de historia de fotografía en España, Madrid, Forren, 1999.

Yáñez Polo, M. A.; Ortiz Lara, L.; Holgado Brenes, J. M. (ed.), Historia de la fotografia española, Sevilla, Sociedad de Historia de la Fotografía Española, 1984.

Anexo 1. Autores y obras del Anuario Fotográfico Español (1924)

\begin{tabular}{|l|l|}
\hline \multicolumn{1}{|c|}{ Autores } & \multicolumn{1}{c|}{ Títulos } \\
\hline Aguiló Casas, M. (Barcelona) & Refugio Ciudadano \\
\hline Algueró, Augusto (Barcelona) & El zinc Caló (El Zíngaro) \\
\hline Andrada, Francisco (Madrid) & Beatas \\
\hline Archilla, P. (Madrid) & Catedral de Toledo \\
\hline Areñas, Rafael (Barcelona) & Retrato \\
\hline Arissa, Antoni (Barcelona) & España Clásica \\
\hline Azcona, José María (Calahorra) & Hacia el Mercado \\
\hline Basas Bardají, Juan (Barcelona) & Nocturno \\
\hline Bausells Brandia, Mateo (Barcelona) & Moll del Peix \\
\hline Belda, J. (Albacete) & Retrato \\
\hline Caldés Arús, V. (Barcelona) & Si esta Ciudadana \\
\hline Cano, P. J. (Melilla) & En el Zoco \\
\hline Castellano, J. (Sevilla) & Uña Cañí \\
\hline Compairé, Ricardo (Huesca) & Alto Aragón \\
\hline Cuesta, F. (Madrid) & Del Puente de Toledo \\
\hline Danís, E. (Madrid) & Uclés (Cuenca) \\
\hline Duarte, G. (Oviedo) & El Maestro Casadó \\
\hline Espadaler, Luis (Barcelona) & Iglesia de Valldoreig \\
\hline Gallifa, M. (Barbastro) & Oración \\
\hline Graupera, J. (Barcelona) & Rincón de mi Tierra \\
\hline
\end{tabular}

Arch. esp. arte, LXXXVII, 348, OCTUBRE-DICIEMBRE 2014, 383-400

ISSN: 0004-0428, eISSN: 1988-8511, doi: 10.3989/aearte.2014.24 
Anexo 1. Autores y obras del Anuario Fotográfico Español (1924) (cont.)

\begin{tabular}{|l|l|}
\hline \multicolumn{1}{|c|}{ Autores } & \multicolumn{1}{c|}{ Títulos } \\
\hline Lasso de la Vega, Manuel F. (Sevilla) & Infraganti \\
\hline Llobet, D. (Sabadell) & La Soledad del Viejo Campanario \\
\hline López, Daniel (Madrid) & Claustro de Belem (Lisboa) \\
\hline López Beaubé, Fernando L. (Ávila) & En la Romería, puesto de caramelos \\
\hline Mañas, José (Albacete) & Descanso \\
\hline Martínez del Carnero, A. (Vigo) & Gerona \\
\hline Martínez Sanz, Vicente (Valencia) & Dómine \\
\hline Massana, Josep (Barcelona) & Estudio \\
\hline Montanya, Pedro (Barcelona) & Marina \\
\hline Novella, Vicente (Valencia) & Retrato \\
\hline Ortiz Echagüe, José (Madrid) & Rosita y su Hermano \\
\hline Prast, Antonio (Madrid) & Idilio \\
\hline Puga (Madrid) & Anochecer \\
\hline Puig Pascual, Esteban (Barcelona) & Coll de Nou Creus (Pirineo Catalán) \\
\hline Retes, Pedro (Madrid) & Piedralabes \\
\hline Revenga, Antonio (Madrid) & Cementerio de Brihuega \\
\hline Reyes, José (Guadalajara) & Cabeza de estudio \\
\hline Sánchez Garća, José (Barcelona) & Vegetación \\
\hline Santa María del Villar, Marqués (Madrid) & Costumbres Navarras \\
\hline Santos Peña, F. (Valladolid) & La Niña de las Uvas \\
\hline Soriano, A. (Madrid) & Rincón de la Moncloa \\
\hline Suñé, S. (Gerona) & Retrato de la Srta. Margarita S. \\
\hline Susanna, Eduardo (Guadalajara) & Las dos Cluecas \\
\hline Tarragó, A. Madrid & La Alambra \\
\hline Torcida, José María (Mytolh's y Granada) & Del Sacro Monte de Granada \\
\hline Torres Molina, Manuel (Granada) & Zambra gitana \\
\hline Trajano (Mérida) & Autorretrato \\
\hline Ventosa, Conde de la (Madrid) & Aguadoras castellanas \\
\hline Vilatobá, Joaquín (Sabadell) & Reposo \\
\hline & \\
\hline
\end{tabular}

Anexo 2. Fotógrafos por provincias en 1946 y 1948

\begin{tabular}{|l|r|r|r|r|r|r|}
\hline \multicolumn{1}{|c|}{ Fotógrafos } & \multicolumn{3}{|c|}{1946} & \multicolumn{3}{c|}{$\mathbf{1 9 4 8}$} \\
\hline Provincia & Capital & $\begin{array}{c}\text { Ciudad } \\
\text { Pueblo }\end{array}$ & Total & Capital & $\begin{array}{c}\text { Ciudad } \\
\text { Pueblo }\end{array}$ & Total \\
\hline Álava & 9 & - & 9 & 9 & - & 9 \\
\hline Albacete & 5 & 23 & 28 & 6 & 22 & 28 \\
\hline Alicante & 17 & 29 & 46 & 17 & 28 & 45 \\
\hline Almería & 9 & 13 & 22 & 9 & 11 & 20 \\
\hline
\end{tabular}


Anexo 2. Fotógrafos por provincias en 1946 y 1948 (cont.)

\begin{tabular}{|c|c|c|c|c|c|c|}
\hline \multirow{2}{*}{$\begin{array}{c}\text { Fotógrafos } \\
\text { Provincia }\end{array}$} & \multicolumn{3}{|c|}{1946} & \multicolumn{3}{|c|}{1948} \\
\hline & Capital & $\begin{array}{l}\text { Ciudad } \\
\text { Pueblo }\end{array}$ & Total & Capital & $\begin{array}{l}\text { Ciudad } \\
\text { Pueblo }\end{array}$ & Total \\
\hline Ávila & 2 & 5 & 7 & 3 & 5 & 8 \\
\hline Badajoz & 6 & 17 & 23 & 6 & 20 & 26 \\
\hline Baleares & 7 & 27 & 34 & 7 & 27 & 34 \\
\hline Barcelona & 139 & 85 & 224 & 133 & 85 & 218 \\
\hline Burgos & 10 & 10 & 20 & 10 & 9 & 19 \\
\hline Cáceres & 3 & 12 & 15 & 3 & 13 & 16 \\
\hline Cádiz & 6 & 31 & 37 & 6 & 28 & 34 \\
\hline Castellón & 6 & 12 & 18 & 6 & 12 & 18 \\
\hline Ciudad Real & 3 & 24 & 27 & 3 & 23 & 26 \\
\hline Córdoba & 7 & 26 & 33 & 7 & 26 & 33 \\
\hline Coruña & 14 & 26 & 40 & 14 & 25 & 39 \\
\hline Cuenca & 4 & 2 & 6 & 4 & 2 & 6 \\
\hline Gerona & 6 & 38 & 44 & 6 & 36 & 42 \\
\hline Granada & 9 & 12 & 21 & 9 & 12 & 21 \\
\hline Guadalajara & 1 & 1 & 2 & 1 & 1 & 2 \\
\hline Guipúzcoa & 20 & 24 & 44 & 20 & 24 & 44 \\
\hline Huelva & 4 & 10 & 14 & 4 & 10 & 14 \\
\hline Huesca & 2 & 11 & 13 & 2 & 10 & 12 \\
\hline Jaén & 4 & 18 & 22 & 4 & 18 & 22 \\
\hline León & 10 & 14 & 24 & 10 & 14 & 24 \\
\hline Logroño & 11 & 3 & 14 & 11 & 3 & 14 \\
\hline Lérida & 4 & 12 & 16 & 4 & 12 & 16 \\
\hline Lugo & 3 & 20 & 23 & 3 & 19 & 22 \\
\hline Madrid & 155 & 22 & 177 & 158 & 22 & 180 \\
\hline Málaga & 19 & 17 & 36 & 19 & 17 & 36 \\
\hline Marruecos & - & 47 & 47 & - & 46 & 46 \\
\hline Murcia & 9 & 30 & 39 & 9 & 31 & 40 \\
\hline Navarra & 5 & 19 & 24 & 5 & 19 & 24 \\
\hline Orense & 4 & 8 & 12 & 4 & 8 & 12 \\
\hline Oviedo & 12 & 31 & 43 & 12 & 32 & 44 \\
\hline Palencia & 6 & 5 & 11 & 6 & 4 & 10 \\
\hline Las Palmas & 14 & 6 & 20 & 14 & 5 & 19 \\
\hline Pontevedra & 3 & 28 & 31 & 3 & 28 & 31 \\
\hline Salamanca & 11 & 11 & 22 & 11 & 11 & 22 \\
\hline Sta. Cruz Tenerife & 4 & 18 & 22 & 4 & 18 & 22 \\
\hline Santander & 7 & 8 & 15 & 8 & 11 & 19 \\
\hline Segovia & 3 & 2 & 5 & 3 & 2 & 5 \\
\hline
\end{tabular}


Anexo 2. Fotógrafos por provincias en 1946 y 1948 (cont.)

\begin{tabular}{|l|r|r|r|r|r|r|}
\hline \multicolumn{1}{|c|}{ Fotógrafos } & \multicolumn{3}{c|}{$\mathbf{1 9 4 6}$} & \multicolumn{3}{c|}{$\mathbf{1 9 4 8}$} \\
\hline Provincia & Capital & $\begin{array}{c}\text { Ciudad } \\
\text { Pueblo }\end{array}$ & Total & Capital & $\begin{array}{c}\text { Ciudad } \\
\text { Pueblo }\end{array}$ & Total \\
\hline Sevilla & 33 & 15 & 48 & 34 & 12 & 46 \\
\hline Soria & 1 & 1 & 2 & 1 & 1 & 2 \\
\hline Tarragona & 4 & 20 & 24 & 4 & 20 & 24 \\
\hline Teruel & 1 & 2 & 3 & 1 & 2 & 3 \\
\hline Toledo & 4 & 12 & 16 & 4 & 12 & 16 \\
\hline Valencia & 49 & 31 & 80 & 49 & 31 & 80 \\
\hline Valladolid & 15 & 3 & 18 & 15 & 3 & 18 \\
\hline Vizcaya & 18 & 8 & 26 & 18 & 8 & 26 \\
\hline Zamora & 5 & 7 & 12 & 5 & 6 & 11 \\
\hline Zaragoza & 31 & 9 & 40 & 31 & 9 & 40 \\
\hline Total & 734 & 865 & 1.599 & 735 & 853 & 1.588 \\
\hline
\end{tabular}

Fecha de recepción: 19-IV-2013

Fecha de aceptación: 17-VI-2014 